\title{
A PROPOSED SUPERCONDUCTING BOOSTER LINAC FOR THE HRIBF
}

\author{
J. D. Bailey, ORNL ${ }^{*} / \mathrm{JIHIR}^{\dagger}$, and D. K. Olsen, ORNL
}

Abstract

A 42 MV Superconducting (SC) Booster Linac is proposed for the Holifield Radioactive Ion Beam Facility (HRIBF). The linac, consisting of 56 superconducting, quarter wave, $120 \mathrm{MHz}$, independently phased, 2 gap resonators, will be used to boost Radioactive Ion Beams (RIBs) accelerated by the $25 \mathrm{MV}$ NEC tandem, to Coulomb barrier energies for use in nuclear physics research near the proton and neutron drip lines. The design potential of $42 \mathrm{MV}$ is sufficient to boost the beams of mass 180 above the Coulomb barrier using the most probable charge state, $15+$, from single foil stripping in the tandem terminal. Linac parameters and layout are presented with accompanying beam dynamic calculations. In addition, an upgrade of the existing pretandem beam bunching system is proposed to further preserve the RIB intensity through better longitudinal phase space matching into the linac.

\section{INTRODUCTION}

HRIBF is providing RIB's for nuclear physics and astrophysics experiments using the ISOL technique. Radioactive atoms are created from nuclear reactions with light-ion beams from ORIC, a compact flexible K100 cyclotron. After diffusing from the target and desorbing from surfaces, these radioactive atoms are ionized, magnetically separated, charge exchanged, and then transported through a second high-resolution separator into the $25 \mathrm{MV}$ tandem, where they are accelerated to energies of interest for nuclear and astrophysics. The tandem is capable of accelerating mass 80 above the Coulomb barrier with single foil stripping in the terminal, and mass 130 above the Coulomb barrier with a second foil stripping $1 / 3$ of the way down the high energy acceleration tube. RIB's are very difficult to produce and have very low intensity, so maximizing the total transmission from the RIB source target to the experimental target is essential.

The Nuclear Science Advisory Committee has identified the National Isotope Separator On Line (ISOL) RIB Facility as the next major construction by the DOE Nuclear Physics program[1]. A possible very cost effective reconfiguration of the existing HRIBF into the National ISOL Facility would be to: (1) use as much of the existing building- 6000 heavily shielded area and experimental apparatus as possible, (2) replace ORIC with an approxinmately $200 \mathrm{MeV}$ ploton - indc br cyclotron, (3) extend the existing RIB injector with a new platform for the production of intense neutron-rich fission fragment RIBs produced by proton bombardment of a high-temperature thick actinide target, and (4) construction of a SC linac booster for the tandem to allow acceleration of fission fragment RIBs above the coulomb barrier with single foil stripping in the tandem[2]. These changes, shown in Fig. 1, will allow physicists to explore nuclei far from stability, learning more about solar processes, and the neutron and proton drip lines.

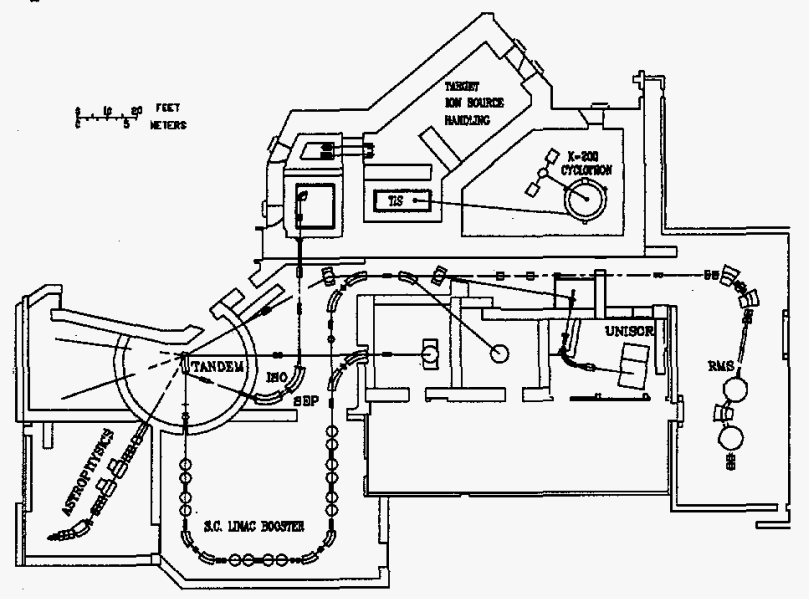

Figure 1 Floor plan depicting the conversion of the HRIBF into the National ISOL Facility. The main changes are a new driver accelerator, a modified target ion source platform, and the addition of a superconducting linac to boost the tandem beam.

These changes can be constructed together or in a phased approach. This paper describes a possible SC linac for this approach. As a booster, this linac could be used to accelerate fission fragment RIBS from ORIC with the existing RIB injector, and from a $200 \mathrm{MeV}$ proton accelerator with a new high-power RIB injector. It can also be built without shutting down the present facility, with only minimal interuptions to the schedule.

\section{LINAC LAYOUT}

The most important requirement for the booster is to accelerate fission fragments above the Coulomb barrier

\footnotetext{
- Research sponsored by the Oak Ridge National Laboratory, managed by Lockheed Martin Energy Research Corporation for the U.S. DOE under contract number DE-AC05-96OR22464.

'The Joint Institute for Heavy Ion Research is the University of Tennessee, Vanderbilt University, and the ORNL; it is supported by the members and by the U.S. DOE under contract number DE-FG05-87ER40361 with the University of Tennessee.

DISTRIBUTION OF THIS DOCUMENT IS UNLIMITEN MASTER

"The submitted manuscript has been authored by a contractor of the U.S. Government under contract No. DE-AC05-96OR22464. Accordingly, the U.S. Government retains a nonexclusive, royalty-free license to publish or reproduce the published form of this contribution, or allow others to do so, for U.S. Government purposes."
}

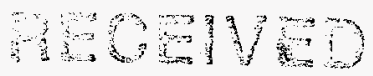

IU: 11907 


\section{DISCLAIMER}

This report was prepared as an account of work sponsored by an agency of the United States Government. Neither the United States Government nor any agency thereof, nor any of their employees, make any warranty, express or implied, or assumes any legal liability or responsibility for the accuracy, completeness, or usefulness of any information, apparatus, product, or process disclosed, or represents that its use would not infringe privately owned rights. Reference herein to any specific commercial product, process, or service by trade name, trademark, manufacturer, or otherwise does not necessarily constitute or imply its endorsement, recommendation, or favoring by the United States Government or any agency thereof. The views and opinions of authors expressed herein do not necessarily state or reflect those of the United States Government or any agency thereof. 


\section{DISCLAMMER}

Portions of this document may be illegible in electronic image products. Images are produced from the best available original document. 
with single stripping which corresponds to the acceleration of $15+$ mass 180 to $5.5 \mathrm{MeV} / \mathrm{A}$. This maximum mass is 180 for two reasons: (1) the maximum fission fragment mass is 180 and the elements with $A>180$ tend to be refractory and will not readily release from targets. To provide RIBs of $A<180$ using the most probable charge state with single stripping with the tandem operating at $22 \mathrm{MV}$ terminal, requires the addition of an effective $42 \mathrm{MV}$ booster linac.

The linac will be similar to the linac at ALPI[3], which provides accelerating fields of $5 \mathrm{MV} / \mathrm{m}$, and is one of the latest in a long line of improvements on heavy ion superconducting booster linacs. Simple niobium quarter-wave resonators with $18 \mathrm{~cm}$ inside diameters will be cooled, by pot boiling of liquid $\mathrm{He}$, in sets of four, inside $\sim 1.1 \mathrm{~m}$ diameter cylindrical stainless steel cryostats. Quarter-wave resonators were chosen because of their wide use, mechanical stability, simple construction, and high accelerating fields.

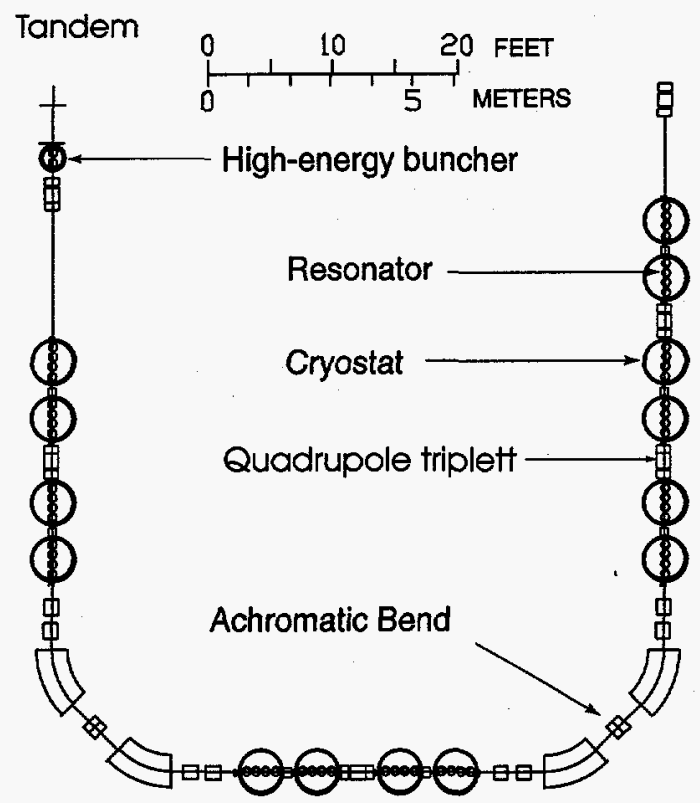

Figure 2 The linac has 14 cryostats, each cooling 4 niobium superconducting $1 / 4 \lambda$ resonators. The configuration depicted uses quadrupole triplets for transverse focusing. Achromatic bends are used to wrap the linac back upon itself.

About 56 resonators operating at $5 \mathrm{MV} / \mathrm{m}$ are needed for an average transit time factor of $95 \%$, using a synchronous phase of 20 degrees, and allowing for a down-time fraction of $5 \%$. Various velocity and frequency configurations of these resonators were investigated in detail to obtain the highest possible energies for $A=6-180$ with single stripping and $A=40$ 238 with a second stripping at the linac entrance. Many configurations are more than adequate; however, the simple and flexible configuration of $56 \beta=0.086$ $120 \mathrm{MHz}$ resonators seems about optimum. Longitudinal phase space matching between the Tandem and the linac, will be achieved with the addition of a high energy buncher before the linac, and a possible modification of the tandem low energy buncher. A high energy chopper may also be added in the tandem exit line. A two frequency linac design was discarded because of a loss of longitudinal phase space.

A possible layout for the booster is shown in Fig. 2. As shown, the linac consists of three sections separated by 90 degree achromatic bends. Quadrpoles, in FODO cells and in doublets and triplets, each separated by one or two cryostats, were investigated to confine the beam radially. Figure 2 shows a round-beam triplet configuration. Other configurations are also acceptable. RIBs could be accelerated by the tandem and transported to the nuclear physics areas with or without the booster. A new $\sim 5000 \mathrm{ft}^{2}$ building will be needed to house the SC linac.

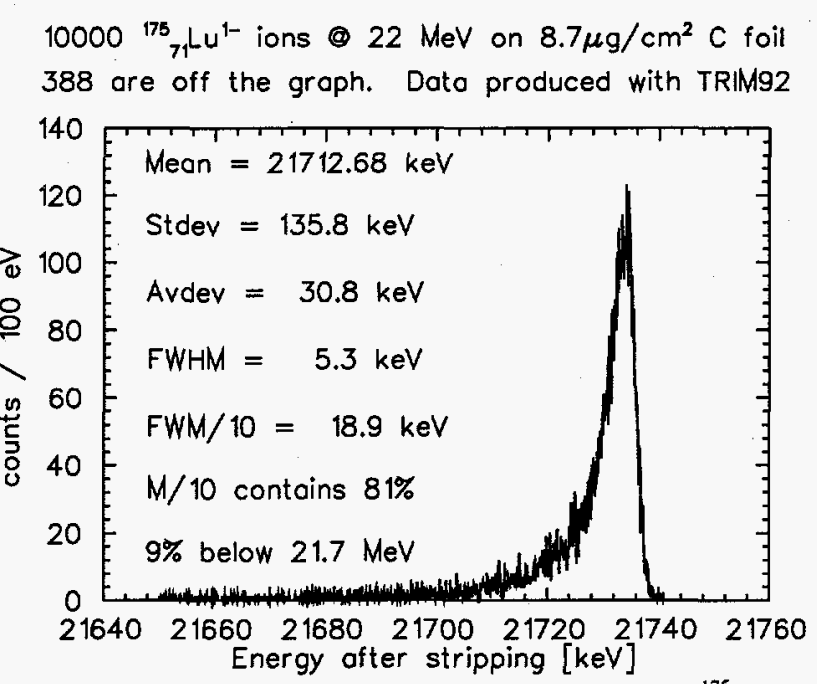

Figure 3 Beam energy spread from stripping ${ }^{175} \mathrm{Lu}$ to $15+$ in an equilibrium thickness ${ }^{12} \mathrm{C}$ foil, in the tandem terminal. This translates into time spreading, and is a major component of the time spreading in the tandem beam $\sim 1 \mathrm{~ns}$.

\section{OPTICS}

The tandem beam has a $1 \pi \mathrm{mm}$ mrad transverse emmittance, with a waist at the exit slits of the tandem[4]. Small energy variations in the tandem translate through the mass and energy analyzing magnets into a small walk in the beam centroid. In high intensity operation, the vertical part of this walk is used to control the tandem potential, and beam energy to $10^{-5}[5]$. For low intensity, the energy can be regulated to $10^{-4}$ using terminal potential stabilizers. Figure 3 shows an energy spread produced by stripping in the tandem terminal calculated with TRIM92[6]. This is typically lower than the tandem energy regulation of $35 \mathrm{keV}$, but because of the long drift path in the tandem terminal, it can dominate the time spreading of the beam. The source 
energy spread is dominated by the charge exchange canal, measured at $50 \mathrm{eV}$ for an As beam.

The low energy buncher will be operated at $10 \mathrm{MHz}$. The present double drift buncher routinely bunches $50 \%$ into $6^{\circ} \mathrm{RF}$, or $1.7 \mathrm{~ns}$. A replacement $4 \mathrm{f}$ buncher based on that of Lynch[7], will bunch $66 \%$ into $4^{\circ} \mathrm{RF}$, or 1.3 ns. A small debunching will occur due to path length differences and beam energy spread and variations. This debunching is $\cong 1 \mathrm{~ns}$. The beam pulse width seen by the high energy buncher will then be $\sim 2 \mathrm{~ns}$.

The high energy buncher, operating at the linac frequency with a $1 \mathrm{f}$ and a $2 \mathrm{f} \mathrm{SC}$ resonator, sees a pulse $\sim 90^{\circ} \mathrm{RF}$ wide with an energy spread of $40 \mathrm{keV}$. As a buncher, it can add about $\pm 1.3 \mathrm{q} \mathrm{MeV}$ to the beam energy spread. Table 1 shows the longitudinal acceptance of the SC linac when operated at a synchronous phase of $15^{\circ}$, for a range of heavy ions, and their most probable charge state after stripping in the tandem terminal at $22 \mathrm{MV}$. The longitudinal acceptance is at maximum energy spread, and does not correspond to maximum phase spread. The corresponding distances to bunch a $2 \mathrm{~ns}$ bunch are also given. An $8 \mathrm{~m}$ drift will be sufficient to longitudinally match the bunched tandem beam to the SC linac acceptance. Figure 2 shows a $5 \mathrm{~m}$ drift length. The extra $3 \mathrm{~m}$ will come at the price of moving a cooling tower, and a 14 in. water pipe.

Table 1 SC Linac longitudinal acceptance at maximum energy spread, and drift length necesarry to bunch a $2 \mathrm{~ns}$ wide bunch, for various beams exiting a $22 \mathrm{MV}$ tandem with the most probable charge state.

\begin{tabular}{|c|c|c|c|c|c|c|c|c|}
\hline $\mathrm{A}$ & 6 & 40 & 80 & 100 & 120 & 140 & 175 & 238 \\
\hline $\mathrm{Q}_{\mathrm{mn}}$ & 3 & 11 & 13 & 14 & 15 & 15 & 15 & $16 / 43$ \\
\hline $\begin{array}{c}\Delta \mathrm{E} \\
\mathrm{MeV}\end{array}$ & 3.8 & 6.6 & 5.4 & 5.2 & 5.8 & 4 & 4.2 & 10 \\
\hline $\begin{array}{c}\Delta \varphi \\
\operatorname{deg}\end{array}$ & 17 & 15 & 13 & 9 & 9 & 8 & 5 & 9 \\
\hline $\begin{array}{c}\mathrm{L}_{\mathrm{hun}} \\
\mathrm{m}\end{array}$ & 5.0 & 5.7 & 6.2 & 6.4 & 5.8 & 7.8 & 6.6 & 2.6 \\
\hline
\end{tabular}

The $90^{\circ}$ achromatic bends present a rather long drift space for the beam to unbunch. This causes a reduction in phase space acceptance, but as shown above, the beam can still be bunched into the reduced phase space, and transmitted through the tandem. If the decision is made to extend the new building addition, it would be advantageous to accelerate only on the first and third legs, using a rebuncher in the middle of the second leg to improve the linac transmission and optics.

The transverse optics are designed by subdividing the linac into cells consisting of two cryostats and a quadrupole triplet. Each cell is designed with a $90^{\circ}$ phase advance. The achromats are designed with point to point focussing.
Figure 4 shows the results of a survey of linac performance over the range of useable fission fragments. Useable is defined as a combination of long half lives, and intense productions[8]. The SC linac will provide Coulomb barrier energies over the entire range.

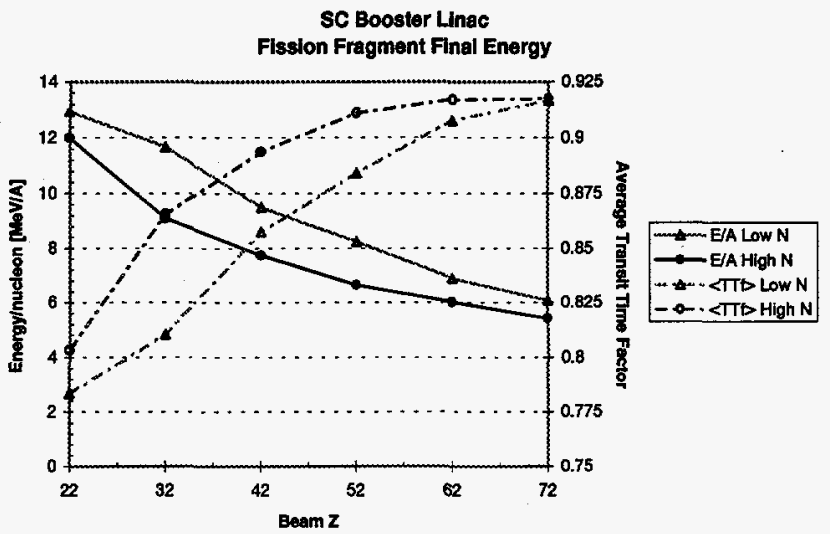

Figure 4 Final beam energy of useable fission fragments as a function of $Z$. Results for both the high and low mass useable fission fragments are shown. Also shown are the corresponding average transit time factors. Optimized for high masses, the SC linac is still efficient over the fission fragment mass range.

\section{REFERENCES}

[1] 'Nuclear Science: A long Range Plan', Nuclear Science Advisory Committee, (DOE/NSF, USA) (1996).

[2] D.K. Olsen, et al.'The National RIB Facility Project.' ORNL Physics Division Progress Report (1996).

[3] A. Facco, et al.'Bulk Niobium Low-, Medium- and High - $\beta$ Superconducting Quarter Wave Resonators for the ALPI Postaccelerator'. 1993 Particle Accelerator Conference. (IEEE, Piscataway) (1993) pp 849-851.

[4] W.T. Milner, et al. 'Transport of DC and Bunched Beams through a $25 \mathrm{MV}$ Folded Tandem'. IEEE Transactions on Nuclear Science, Vol. NS-22, No. 3 (1975), pp. 1697-1701.

[5] D.K. Olsen, et al. 'Calibration of the HHIRF Tandem Accelerator Energy Analyzing Magnet.' NIM A254 (1987) pp 1-6.

[6] J.F. Ziegler, et al. 'The Stopping and Range of Ions in Solids.' (Pergamon Press, New York) (1985).

[7] F.J. Lynch, et al. 'Beam Buncher for Heavy Ions.' NIM A159 (1979) pp 245-263.

[8] Private communication - J. Garret, ORNL (1997). 